\title{
Competições de programação para meninas do ensino médio: Afinal, era apenas uma questão de propósito!
}

\author{
Gláucia Braga e Silva ${ }^{1}$, Thais Regina de M. B. Silva ${ }^{1}$, Maria Dalila Vieira ${ }^{1}$ \\ ${ }^{1}$ Instituto de Ciências Exatas e Tecnológicas \\ Universidade Federal de Viçosa (UFV) - campus Florestal \\ \{glaucia, thais.braga, maria.dalila\}@ufv.br
}

\begin{abstract}
Resumo. Este trabalho investiga o quanto o perfil de competições de programação voltadas para meninas do ensino médio/técnico influencia na motivação das mesmas em competir. Para isso, foram coletados dados de participações em 4 competições, no triênio 2017-2019, sendo 2 tradicionais maratonas de programação e 2 com foco em empreendedorismo e tecnologia. Para a amostra considerada, observada por meio de parâmetros tais como curso de origem e participações totais no triênio, os resultados mostraram que as meninas têm mais interesse em participar das competições de empreendedorismo e tecnologia aplicada.
\end{abstract}

\section{Introdução}

Este trabalho investiga o quanto o perfil de competições de programação voltadas para meninas do ensino médio/técnico influencia na motivação das mesmas em competir. A participação nestas competições faz parte das ações extensionistas realizadas por projetos executados no âmbito de um programa de extensão chamado MinasCoders, realizado na Universidade Federal de Viçosa - campus Florestal (UFV/Florestal). Essas ações vem sendo realizadas como forma de atrair, motivar e fixar meninas nas áreas de informática e computação, no contexto dessa Instituição de Ensino Superior (IES). Dessa forma, por meio da apresentação de dados reais, coletados ao longo de 3 anos da execução de atividades de treinamento e participação em competições, nosso objetivo é avaliar a hipótese de que o senso do propósito e a possibilidade de aplicação concreta do que se está desenvolvendo são elementos fundamentais para estimular a participação das meninas.

Este trabalho está organizado como segue: a seção 2 apresenta os trabalhos relacionados; As seções 3 e 4 trazem, respectivamente, a metodologia adotada e as competições consideradas; A seção 5 apresenta os dados coletados e as discussões acerca da hipótese levantada. Por fim, a seção 6 traz as considerações finais do estudo.

\section{Trabalhos relacionados}

Embora ainda de forma restrita, é possível encontrar na literatura trabalhos que reportam a participação feminina em maratonas de programação. Em [Silva et al. 2018] os autores mencionam o envio de uma equipe de alunas para participação na maratona da Sociedade Brasileira de Computação (SBC) como uma das estratégias para a permanência e o êxito de mulheres em cursos superiores da área de TI. O trabalho em [de Freitas et al. 2016] apresenta uma lista com os resultados das participações de meninas em competições, dentre elas, a maratona da SBC e a Olimpíada Brasileira de Informática (OBI). Em ambos os trabalhos, o recorte do público atendido contempla apenas alunas de nível superior. Não são apresentados e analisados dados, limitando-se os autores a mencionarem 
o ano e a colocação obtida pelas equipes de meninas participantes. Uma outra gama de trabalhos têm abordado o uso de competições como a Technovation Girls (TG), anteriormente chamada Technovation Challenge, para despertar o interesse de estudantes do ensino médio/técnico pela área de tecnologia. Em [Santiago and Andrade 2018], um panorama geral sobre a participação na TG de equipes provenientes de oito estados brasileiros é apresentado. A importância do estudo está na investigação sobre a relevância da competição em si. [Ridel et al. 2018] descrevem a realização de um evento local cujo objetivo era apresentar para meninas de 10 a 18 anos a TG, bem como motivá-las a participar. Os autores informam a agenda do evento, o número de meninas e mentores participantes e a quantidade de alunas que seguiram participando de fato da competição.

O trabalho atual difere daqueles apresentados acima, pelo fato de apresentar dados coletados sobre a participação de meninas do ensino médio/técnico, e discutir a hipótese de que, para este recorte, o foco das competições possui relevância estratégica.

\section{Metodologia}

Este estudo apresenta dados referentes às participações de meninas do ensino médio/técnico da UFV/Florestal em 4 competições de programação no triênio 2017-2019, sendo 2 competições envolvendo programação de forma direta e $2 \mathrm{com}$ foco em empreendedorismo e tecnologia. Essas participações foram coordenadas por atividades do programa MinasCoders. Foram coletados dados quantitativos referentes ao número de participantes em cada uma das competições selecionadas, por meio de acesso às listas de inscritos, seja nos registros locais do MinasCoders e/ou nos sites das competições. A partir dos dados coletados, foram gerados gráficos e tabelas, com o intuito de se identificar a influência do perfil da competição na motivação e no interesse das meninas, em função do número de participações. Os dados foram apresentados segundo os seguintes parâmetros: a) participações por competição em cada ano; b) participações por curso técnico de origem; e c) participações totais no triênio por perfil da competição.

\section{A participação em competições no triênio 2017-2019}

\subsection{Competições consideradas}

- Maratona de Programação da Semana da Computação Jr (Maratona Local), é uma competição promovida pelo curso Técnico em Informática oferecido pela escola técnica vinculada à UFV/Florestal;

- OBI - Olimpíada Brasileira de Informática ${ }^{1}$;

- TG - Technovation Girls², uma competição mundial de tecnologia e empreendedorismo, que objetiva inspirar e educar meninas dos ensinos fundamental e médio a solucionar problemas reais de suas comunidades usando tecnologia;

- Change The Game ${ }^{3}$, uma iniciativa do Google Play para apoiar e incentivar a representatividade feminina no mundo dos jogos para celular.

\subsection{Recrutamentos e treinamentos}

Em 2017, após definição das competições alvo, estabeleceu-se um cronograma que teve como ponto de partida a realização de visitas às salas de aula de todos os anos do curso

\footnotetext{
${ }^{1}$ https://olimpiada.ic.unicamp.br/info/

${ }^{2} \mathrm{https} / / / \mathrm{www} . t e c h n o v a t i o n b r a s i l . o r g /$

${ }^{3} \mathrm{https}: / /$ play.google.com/about/changethegame/
} 
Técnico em Informática. Naquele momento, o foco eram as competições OBI e a Maratona Local. O modelo de treinamento era rígido, com encontros de 2 horas de duração às sextas-feiras à tarde. Uma das meninas da equipe do MinasCoders, aluna do bacharelado em Ciência da Computação, se voluntariou a ensinar conceitos de programação e linguagem $\mathrm{C}$, bem como a trabalhar exercícios de versões anteriores da OBI.

No ano de 2018, para divulgação e recrutamento, as ações foram executadas em dois momentos e, em cada um deles, de formas diferentes. No 1o semestre, ainda com o intuito de estabelecer um grupo de treinamento para OBI e para a Maratona Local, foram feitas novamente visitas às salas de aula. No 2o semestre, foi aplicada uma dinâmica de apresentação da competição TG e criado um grupo de Whatsapp para inscrição das interessadas e esclarecimento de dúvidas. Em ambos os momentos foram realizadas ações de elaboração de cartazes físicos e virtuais. No 1o semestre, os treinamentos foram realizados às sextas-feiras, de 13 às $15 \mathrm{~h}$, sendo conduzidos por duas alunas de graduação bolsistas dos projetos vinculados ao MinasCoders e seguindo a mesma sistemática utilizada no ano de 2017. Após a ocorrência das duas competições inicialmente pretendidas, houve uma redefinição de foco e seleção de nova competição alvo: a TG. No início do 2o semestre, foi estabelecido um novo grupo que realizou, até Maio de 2019, um novo formato de treinamentos, moldado sobre o cronograma de atividades da própria competição TG e contando com encontros presenciais e remotos. O horário para a parte presencial foi estabelecido em conjunto com as meninas, sendo uma vez por semana, das 12 às $13 \mathrm{~h}$ (intervalo de almoço). Os treinamentos envolviam programação, marketing e negócios.

No ano de 2019, o programa MinasCoders realizou atividades de divulgação e recrutamento inicialmente para a temporada 2019/2020 da TG e, posteriormente para uma nova competição, a Change the Game. As estratégias usadas seguiram aquelas formuladas no 20 semestre do ano anterior. As atividades de treinamento para as equipes formadas para a TG 2019/2020 se iniciaram em Dezembro de 2019 e tem sido conduzidas, conforme calendário da competição, até o momento da submissão deste trabalho. Seguindo a dinâmica utilizada no ano anterior, as meninas seguem se encontrando presencialmente, em horários por elas estabelecidos, e de maneira remota. Para a Change the Game, os treinamentos também ocorreram nas modalidades presenciais e à distância, sendo conduzidos por integrantes do MinasCoders. Para o ano de 2019 não havia previsão de recrutamento e treinamento para a OBI. Porém, uma inesperada demanda por parte de algumas meninas ocorreu, levando à realização de algumas atividades de treinamento.

\section{Resultados}

Esta seção apresenta os dados coletados, sob diferentes perspectivas, com o intuito de se identificar possíveis relações entre o perfil das competições e o comportamento do público-alvo. Inicialmente, foi feita uma contabilização das participações nas 4 competições citadas na subseção 4.1, no triênio 2017-2019, conforme mostra a Tabela 1.

Conforme podemos observar na Tabela 1, para a Maratona Local só temos os dados de 2018, pois só houve uma edição desta no triênio considerado. Para a competição TG, não tivemos participações em 2017. Da mesma forma, só houve participação na competição Change The Game em 2019. Para a OBI, a primeira competição alvo do MinasCoders, tivemos uma queda nas participações de 2017 para 2018 e um pequeno aumento em 2019. Importante destacar que em 2017 e 2018, 2 das competidoras (2/3 e 2/2, 
Tabela 1. Participantes $x$ Competição no Triênio

\begin{tabular}{l|l|l|l} 
Competição/Ano & $\mathbf{2 0 1 7}$ & $\mathbf{2 0 1 8}$ & $\mathbf{2 0 1 9}$ \\
\hline OBI & 3 & 2 & 4 \\
\hline Maratona Local & 0 & 2 & 0 \\
\hline TG & 0 & 7 & 12 \\
\hline Change The Game & 0 & 0 & 3 \\
\hline & \multicolumn{2}{|l}{}
\end{tabular}

respectivamente) eram bolsistas do MinasCoders e, por conta disso, foram encorajadas a participar. Por outro lado, em 2019, apenas uma participante era bolsista e as outras 3 meninas tinham participado da competição TG em 2018. Esses números, somados às observações das coordenadoras do MinasCoders, parecem indicar que a participação na competição TG teve um impacto positivo em termos de motivação e empoderamento das meninas, que se mobilizaram para participarem da OBI em 2019, ainda que o MinasCoders não tenha coordenado a participação nesta edição. $\mathrm{O}$ mesmo parece ter acontecido em relação à competição Change The Game, já que as 3 participantes em 2019 também haviam participado da TG em 2018. Com relação à competição Change The Game, destacamos que uma de nossas meninas ganhou menção honrosa na ocasião. Também é possível observar, a partir dos dados coletados, que a competição TG se evidencia em relação às demais quanto ao número de participações, pois além de em 2018 este número ser maior que as participações em todas as outras competições no triênio, houve um aumento significativo em 2019 (70\%).

Também observamos uma particularidade em relação à competição TG, no que compete ao poder de atração de meninas de diferentes cursos técnicos. O gráfico da Figura 1(a) apresenta os cursos técnicos de origem de cada participante, nas edições de 2018 e 2019. Embora sejam apenas duas edições, já se observa um aumento tanto do número de participações por curso quanto da variedade de cursos envolvidos. Importante ressaltar que muitas destas participações de meninas de outros cursos, fora da área de TI, foram de iniciativa das próprias meninas.

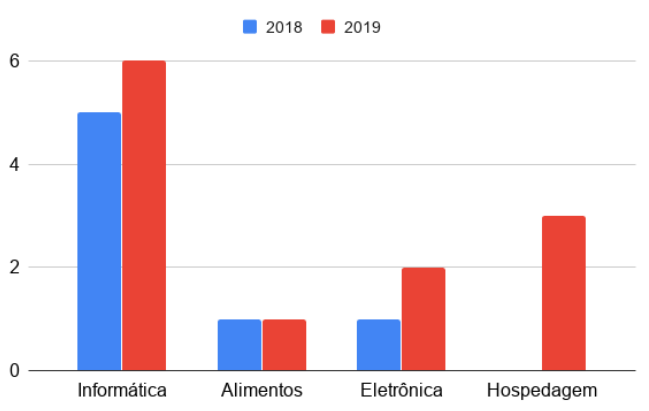

(a) Meninas por Curso Técnico no triênio - TG

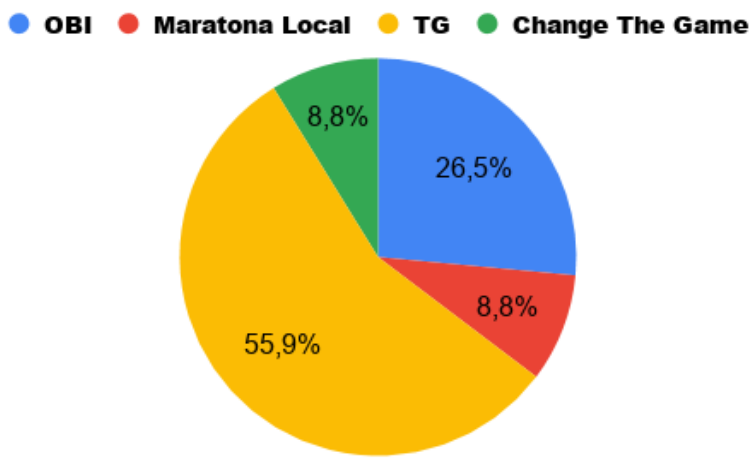

(b) Participantes totais por competição no triênio

Figura 1. Participações por curso e participações totais

Por fim, o gráfico da Figura 1(b) apresenta as participações totais por competição no triênio. Nele, podemos observar que as competições de empreendedorismo e tecno- 
logia, TG e Change The Game, abrangeram $64.7 \%$ das participações no triênio, com destaque para a TG que totalizou $55.9 \%$ de participações. Esses números somados ao entusiasmo das meninas, constantemente observado nos encontros presenciais, são fortes indicadores do potencial desse estilo de competição, em termos de motivação deste recorte de público alvo, quando comparado às tradicionais maratonas de programação, como OBI, por exemplo.

Considerando os dados apresentados, podemos fazer uma reflexão acerca da influência dos perfis das competições consideradas no nível de interesse e motivação das meninas, a partir das seguintes conjecturas: 1) Competições tradicionais de programação não parecem atrair o interesse deste público porque as meninas não conseguem vislumbrar como os códigos produzidos podem ser utilizados em uma aplicação final; 2) Competições de empreendedorismo e tecnologia aplicada trabalham a programação de uma forma mais lúdica e com aplicação direta na solução de problemas reais; e 3) Competições de empreendedorismo e tecnologia aplicada permitem a participação de meninas de outras áreas por não exigirem habilidades de programação como pré-requisito.

\section{Considerações finais}

Este trabalho apresentou dados coletados sobre a participação de meninas de nível médio/técnico, em diferentes tipos de competições. A partir dos dados, foram realizados relatos e prospecções sobre a efetividade do uso de tais competições como forma de atrair e motivar meninas quanto à área de TI. Foi possível observar, sob diferentes parâmetros, que existem diferenças marcantes ligadas ao estilo da competição.

Como trabalhos futuros, pretende-se continuar a coleta dos dados após edições futuras das competições, como forma de viabilizar uma análise de tendências. Além disso, realizar uma coleta de dados via formulários com as participantes, de maneira a obter visões que possam esclarecer, corroborar e/ou instigar novas análises.

Agradecimentos Ao apoio financeiro dos parceiros PEC/UFV ${ }^{4}$ e SetApp. ${ }^{5}$

\section{Referências}

de Freitas, R., Lobo, L., and Conte, T. (2016). Projeto scitechgirls: desenvolvimento de aplicativos e participação em competições de programação científicas e tecnológicas. In $10^{\circ}$ Women in Information Technology (WIT 2016), volume 10, Porto Alegre, RS, Brasil. SBC.

Ridel, D., Tridico, S., Branco, L. H. C., Maldonado, J. C., and Branco, K. C. (2018). Technovation hackday @ icmc-usp um instrumento de difusão e articulação de meninas na computação. In $12^{\circ}$ Women in Information Technology (WIT 2018), volume 12, Porto Alegre, RS, Brasil. SBC.

Santiago, S. and Andrade, C. R. d. (2018). Iniciativas de inserção de mulheres no mercado de tecnologia da informação: Análise das experiências de participantes brasileiros do desafio technovation. In $12^{\circ}$ Women in Information Technology (WIT 2018), volume 12, Porto Alegre, RS, Brasil. SBC.

Silva, J. B. d., Braga, R. B., and Oliveira, C. T. (2018). Estratégias para permanência e Êxito de estudantes mulheres em cursos superiores de tecnologia da informação e comunicação. In $12^{\circ}$ Women in Information Technology (WIT 2018), volume 12, Porto Alegre, RS, Brasil. SBC.

\footnotetext{
${ }^{4}$ http://www.pec.ufv.br/

${ }^{5}$ https://www.setappufv.com.br/
} 